\title{
DINÁMICA MICROBIANA EN VERMICOMPOSTAS COMERCIALES CON Y SIN INOCULACIÓN DEL HONGO Trichoderma spp.
}

\author{
VILMA AMPARO HOLGUIN CASTAÑO${ }^{1}$ y JAIRO MORA-DELGADO ${ }^{2}$ \\ vholguin@ut.edu.co
}

Manizales, 2009-08-29 (Rev. 2009-10-02)

\section{RESUMEN}

En el presente trabajo se presentan los resultados de un ensayo en el cual se evaluó la efectividad de la inoculación del hongo Trichoderma spp, en una vermicomposta comercial, comparándose ésta con la población del hongo presente en un vermicompost sin inocular. El experimento se realizó en el laboratorio de postcosecha de la Universidad de Costa Rica. Se desarrolló en tres fases (cultivo, aislamiento e inoculación de cepas del hongo) y se utilizaron tres vermicompostas comerciales elaboradas a partir de un sustrato de broza de café, procedentes de diferentes composteras. Los resultados muestran que no hubo aumento ni disminución de la población de Trichoderma como producto de la inoculación de cepas del mismo.

\section{PALABRAS CLAVE:}

Vermicomposta, Trichoderma, supresividad, inóculo.

\section{MICROBIAL DYNAMICS IN COMMERCIAL VERMICOMPOSTS WITH AND WITHOUT TRICHODERMA SPP. FUNGUS INOCULATION}

\begin{abstract}
In tThis paper, presents the results are presented onof the growthefectiveness of the Trichoderma fungus in a inoculation in a commercial vermicompost, in comparison with the fungus from a vermicompostand without inoculation. In a three-phase laboratory process (cultivation, isolation and inoculation of fungal strains), three different commercial vermicompost, prepared from coffee pulp, have beenwere used, coming from three different commercial vermicomposts. The results of experiments carried out in the Post-Harvest Laboratory of the Universidad de Costa Rica, don't show any increase or decrease of the Trichoderma population after inoculation. The experiment was carried out in the Post -harvest Laboratory of University of Costa Rica. It was developed following three phases, using three commercial vermicompost prepared with broza of coffee. Results showed no differences in Trichoderma population as product of inoculation of it into the compost.
\end{abstract}

KEY WORDS: Vermicompost, Trichoderma spp., suppressive, inoculums.

\section{INTRODUCCIÓN}

En los últimos años se ha trabajado con la inoculación del hongo Trichoderma en las compostas, con el fin de que éstas presenten un efecto supresivo para el control de patógenos del suelo. Los resultados han sido satisfactorios en la mayoría de casos, pero en otros el efecto de la inoculación no ha sido significativo.

Se ha mencionado que la inoculación del compost con microorganismos, tiene influencia en la calidad y en el efecto supresivo para el control de patógenos de plantas. Weindling en 1932, había hecho trabajos pioneros sobre Trichoderma spp como agente de biocontrol (Freenman, 1981) y Hoitink et al (1993) hace una extensa revisión de los efectos supresivos de Trichoderma spp en sustratos enmendados con compost. Sin embargo, aún se encuentran muchos vacíos en cuanto al aumento de la población del hongo inoculado respecto a la población nativa del mismo. 
En los desechos orgánicos utilizados en el proceso de compostaje, normalmente se encuentran una serie de microorganismos, tales como bacterias, hongos y actinomicetos, capaces de llevar a cabo los procesos de degradación de las sustancias complejas y síntesis bioquímica de nuevas sustancias (Lynch, 1993; Corlay et al., 1999). Estos microorganismos, capaces de llevar a cabo la degradación y síntesis, necesitan una serie de condiciones ambientales para su supervivencia. Entre estas condiciones ambientales para favorecer el crecimiento de ciertos microorganismos hay que tener en cuenta la aireación, la humedad, el oxígeno, el tipo de alimento para la reproducción y la disponibilidad de nutrientes como N, P y K presentes en los materiales de desecho (Dallzell et al., 1987).

Durante los últimos veinte años se ha compilado suficiente información sobre las propiedades supresivas de las compostas sobre las enfermedades causadas por hongos. La supresividad del compost para los microorganismos patógenos de la planta en el suelo es afectada por una diversidad de factores, entre ellos, los procesos de calentamiento pueden erradicar los patógenos de las plantas. Otros factores ambientales, como el sistema de compostaje usado, el porcentaje de humedad del compost y la composición del sustrato, pueden afectar las poblaciones microbianas, principalmente microorganismos mesofílicos, después del pico de calentamiento en el proceso de compostaje (Hoitink et al., 1993).

Los mecanismos que han sido descritos en la actividad de los agentes de control biológico contra los patógenos del suelo son: competencia por nutrimentos (carbono y hierro), antibiosis, hiperparasitismo y protección inducida. La literatura sobre compostas describe la microbiostasis (competición o antibiosis) e hiperparasitismo como los principales mecanismos (Hoitink et al., 1993).

El uso de hongos antagonistas para el control de patógenos del suelo es de mucha importancia en las últimas décadas. Aunque el antagonismo a varios hongos es fácilmente demostrable en suelo estéril, intentos para controlar enfermedades por inoculación directa en suelo natural han fallado o han dado resultados inconsistentes (Henis, 1984). Esta situación fue resumida por Garret (1965) citado por Henis (1984), quien relacionó esta falla con la poca oportunidad de un organismo extranjero de ser adaptado por sí solo en un medio ambiente extraño, el cual está ya colonizado en su total capacidad ecológica. Una opinión similar fue expresada por Alexander (1971) citado por Henis (1984) quien concluyó que "que tales intentos fueron perdidos ya que el inoculante que contenía organismos foráneos fue inferior a la microflora nativa del suelo". Sin embargo, a pesar del gran número de puntos de vista pesimistas, no se puede ignorar el creciente número de reportes sobre el control exitoso de enfermedades causadas por patógenos del suelo por la aplicación directa de antagonistas.

Algunos de los antagonistas que se han comportado exitosamente bajo condiciones de laboratorio y campo, como los aislamientos de Trichoderma spp, han sido estudiados en detalle y han mostrado resultados promisorios, especialmente para el control de Rhizoctonia solani y Sclerotium rolfsii. Igualmente la supresividad de los suelos contra patógenos de las plantas ha sido asociada con la presencia de Trichoderma spp bajo condiciones de laboratorio y campo (Henis, 1984).

En el presente estudio se analizó la carga microbiana de vermicompostas comerciales y se evaluó la efectividad de la inoculación del hongo Trichoderma spp, en una muestra del mismo abono, comparándose con la población del hongo presente en un vermicompost sin inocular. Los objetivos del ensayo fueron: 1. Estimar las poblaciones microbianas de hongos, bacterias y actinomicetos en tres vermicompostas comerciales; 2. Estimar la cantidad del hongo Trichoderma spp presente en las tres vermicompostas; 3. Aislar una cepa del hongo Trichoderma spp de un vermicompost seleccionado; 4. Evaluar el efecto de inoculación de una cepa de Trichoderma spp en una vermicomposta comercial, sobre el crecimiento de la población del hongo.

\section{MATERIALES Y MÉTODOS}

El experimento se realizó en el laboratorio de postcosecha de la Universidad de Costa Rica. Se desarrolló en tres fases y se utilizaron tres vermicompostas comerciales, elaboradas a partir de un sustrato de broza de café, procedentes de diferentes composteras. A estas se les hizo un recuento de las poblaciones microbianas (hongos, bacterias y actinomicetos), mediante el método de conteo directo en plato. Dos de los vermicompost habían sido previamente inoculados con Trichoderma spp. 
En la primera fase se realizó un cultivo en plato con muestras de vermicomposta para determinar la población microbiana. A partir de 1 gramo de muestra de vermicompost diluido en $60 \mathrm{ml}$ de agua, se tomó $1 \mathrm{ml}$ y se lo colocó en 9 de agua para proceder al cultivo. Se realizaron 5 diluciones (1/60; 10-1; $10-2 ; 10-3 ; 10-4)$. De cada una de las diluciones se sembró $0.1 \mathrm{ml}$ en cada caja petry con el medio de cultivo Papa-Dextrosa-Agar (P.D.A.). Esto incrementa la dilución por un factor de 10, para el cálculo del número de microorganismos en el vermicompost. De cada dilución se hicieron cuatro repeticiones.

En la segunda fase, del compost C1 -no inoculado- se escogió la muestra que presentaba la mejor población del hongo Trichoderma spp -detectada mediante la técnica de dilución- para proceder a inocular el hongo. De éste se realizaron varios aislamientos multiplicándolos en un medio de cultivo PDA + ácido láctico (1 gota). Se seleccionó el aislamiento que presentaba mayor crecimiento, producción de esporas y tinción del medio cultivo.

En la tercera fase se procedió a inocular el vermicompost. Para tal efecto, se determinó la concentración, mediante la técnica del conteo de esporas, utilizando un hemocitómetro o cámara "Neubauer". Ésta consiste de una lámina de cristal de una dimensión aproximada a la de una lámina de portaobjetos, pero de mayor grosor, tiene ranuras en forma de $\mathrm{H}$, con rieles a cada lado que sostienen un cubre objeto grueso especial a una distancia de $0.1 \mathrm{~mm}$ por encima de las dos porciones interiores de la $\mathrm{H}$, que forman dos cámaras entre éstas y el cubreobjetos. El fondo de cada una de las cámaras tiene un rayado "Neubauer" de $9 \mathrm{~mm} 2$ (3 mm por lado) dividido en 9 cuadrados principales (C.P.) de 1 $\mathrm{mm}$ por lado, de los cuales se cuenta arbitrariamente el contenido de cinco: los cuatro de las esquinas y el central. Esto con el fin de calcular la concentración de propágalos, cuando éstos son relativamente grandes. Aquí se usó la fórmula para propágulos pequeños, haciendo conteos en una fracción del C.P. central.

Para el conteo, se preparó en agua una suspensión de los propágulos a contar, se les agregó una gota de tween 80 y se puso a agitar en un beaker con una barra magnética durante aproximadamente 5 minutos.

Los tratamientos se separaron en palanganas plásticas, conteniendo $1 \mathrm{Kg}$ de vermicompost cada una. La concentración de hongo a inocular en el compost se hizo en una dilución de $0.5 \%$. El vermicompost inoculado recibió una concentración inicial de 1.2 x 104 propágulos gr-1 compost. Se emplearon cuatro repeticiones para cada uno de los tratamientos. A las cuatro palanganas del tratamiento testigo se les adicionó $200 \mathrm{ml}$ de agua destilada. Cada uno de los tratamientos se mezcló manualmente para obtener una pasta uniforme. Finalmente, se procedió a tapar y marcar las palanganas; cada dos días se hicieron volteos del compost, agitando las palanganas durante 1 minuto aproximadamente. Esto con el objeto de airear el sustrato, controlar la temperatura y distribuir el inóculo del hongo.

A los 8 días siguientes a la inoculación, se tomó una muestra de compost y se puso a secar a $30^{\circ} \mathrm{C}$ por 48 horas. Después de secado se tomó 1 gramo de compost de cada tratamiento para hacer el cultivo en los platos, con cuatro repeticiones por cada dilución decimal $(1 / 60 ; 10-1 ; 10-2 ; 10-3)$ y se realizaron conteos a los 3, 5 y 8 días de incubación.

\section{RESULTADOS Y DISCUSIÓN}

Los hongos constituyen la especie de microorganismos predominantes en los abonos evaluados. Esto se explica por la habilidad de estos microorganismos por sobrevivir en medios ácidos. En la figura 1 se puede observar que el tratamiento que presentó el mayor número de hongos fue el C1 con una población de 6.9 x103 propágulos / gr de compost, seguido del C3, cuya población representa el 78\% respecto al anterior y el C2 representa el 40.5\% con respecto al C1. La gráfica denota un dominio de bacterias y hongos en $\mathrm{C} 1$ 


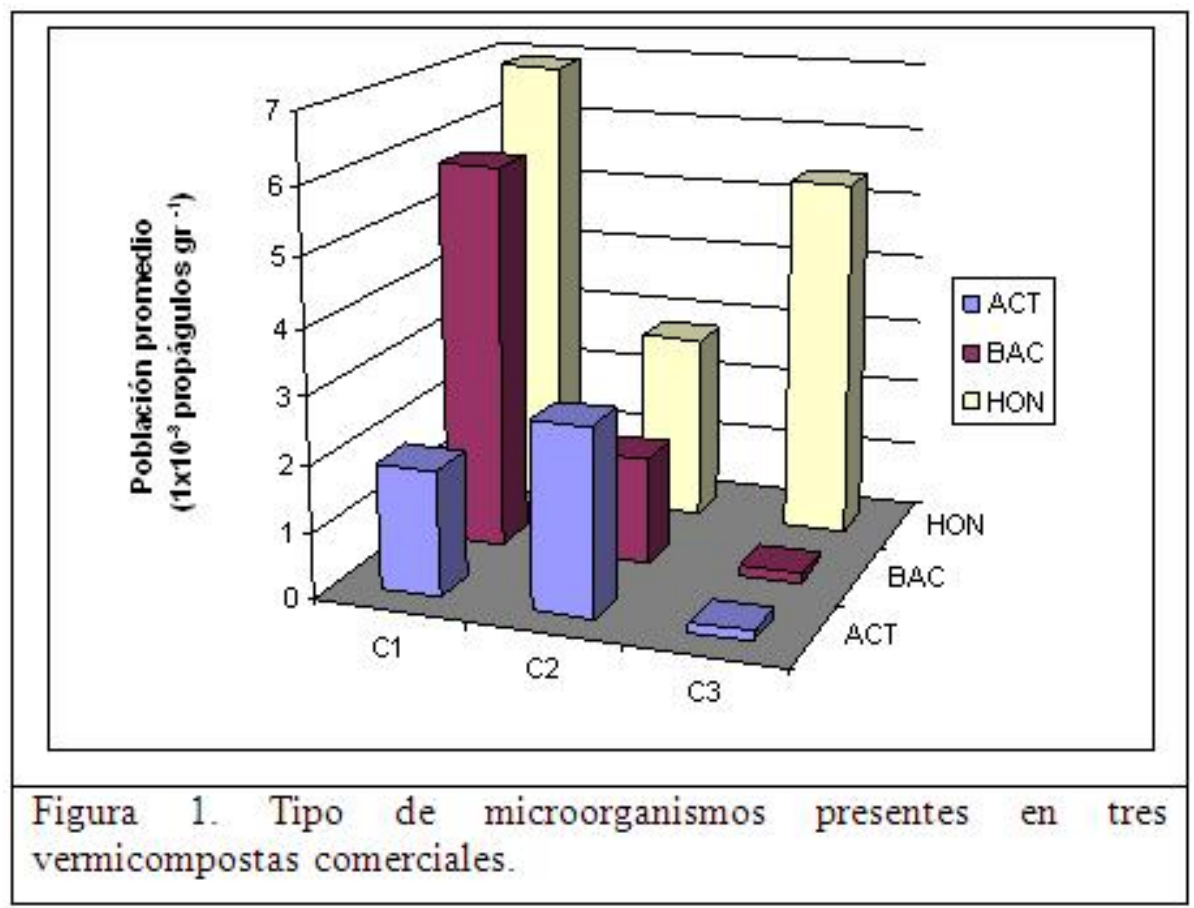

En términos generales, la gráfica sugiere una mejor distribución entre hongos y actinomicetos, aventajando ligeramente a bacterias en C2; podría inferirse que este vermicompost tuvo una menor población microbiana, pero más uniforme. Respecto a la población de bacterias, se puede observar que C1 también presentó la mayor población 5.8 x 103 seguido de C2, el cual tuvo una población de 27.5\% con respecto a la anterior; el C3 representa un $25 \%$ con respecto al C1.

El C3 presentó una significativa dominancia de hongos, respecto a bacterias y actinomicetos. En cuanto a la población de actinomicetos, en la gráfica se puede observar que el C2 muestra la mayor población, con un 2.8 x 103 propágulos / gr de compost, seguido del C1 que representa el $67.8 \%$ con respecto al anterior y el C3 representa un 53.5\% con respecto al C2.

Los datos obtenidos sugieren que la diferencia en las poblaciones microbianas está relacionada con la calidad de los sustratos y tipo de manejo (v.gr. frecuencia de volteos, humedad, temperatura etc.). Según Lynch (1993) en las etapas iniciales de los procesos de compostaje para la fermentación los microorganismos utilizan preferencialmente carbohidratos simples con la eventual producción dióxido de carbono, agua y energía. En las etapas posteriores al compostaje, cuando la mayoría de las formas de carbono simple y las fuentes de nitrógeno se han terminado, es notable un cambio en los grupos microbiales.

En el conteo en plato realizado a los tres y cinco días siguientes a la inoculación se pudo detectar la presencia de hongos y bacterias, pero fue difícil identificar el hongo Trichoderma spp en esta lectura. Sólo se pudo identificar el hongo hasta los 8 días siguientes. 


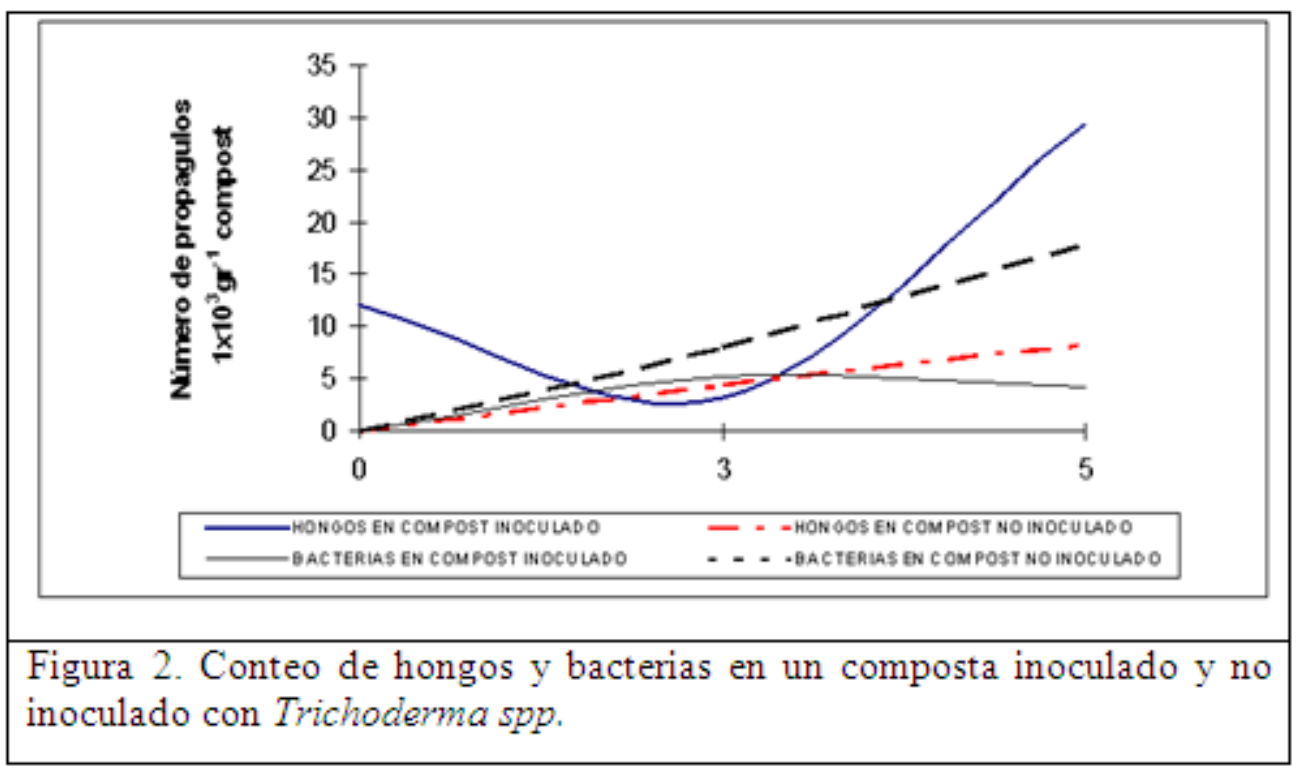

En la figura 2 se muestra cómo el compost inoculado, con una concentración inicial de 1.2×104 propágulos gr-1 de compost, muestra inicialmente un decrecimiento en el número de hongos a los 3 días y después hay un incremento entre los 5 y 8 días. Esto puede deberse a que se presenta una situación de estrés en el momento de la inoculación, probablemente el hongo no encontró las condiciones propicias, principalmente, en lo relacionado con la disponibilidad de nutrimentos de fácil asimilación. Al respecto Heinis (1984) advierte la poca oportunidad de un organismo extranjero de ser adaptado por sí solo en un medio ambiente extraño el cual está ya colonizado en su total capacidad ecológica.

Lo anterior, puede estar relacionado con el hecho que el vermicompost inoculado era un abono maduro en el cual los compuestos de fácil degradabilidad, como azúcares simples y compuestos nitrogenados, ya han sido agotados en su mayor parte en la etapa termofílica (Dalzell et al., 1987). En los estados de madurez del compost quedan sustancias altamente resistentes a la degradación como lignina, celulosa y hemicelulosa, las cuales son aprovechadas por algunos hongos y actinomicetos (Lynch, 1993). Es probable que el incremento en la población de hongos, observado después de los tres días, obedezca a un proceso de mejor adaptación del hongo a las condiciones ambientales.

Es notorio también el escaso crecimiento de la población bacteriana en contraste con el incremento de la población de hongos, incluso presenta un ritmo de crecimiento menor que la población de bacterias en el compost no inoculado. Esto puede deberse al efecto supresivo ejercido por el hongo Trichoderma sobre los otros microorganismos del medio mediante, asociaciones tróficas de competencia por nutrimentos o antibiosis (Hoitink, 1993; Alexander, 1977).

Se puede suponer también que las partículas del agar donde se reprodujo el hongo y que van adheridas en el momento de la inoculación, pueden haber constituido un sustrato apropiado para la alimentación de los hongos y las bacterias presentes en el compost.

En el vermicompost que no fue inoculado, claramente se puede observar que el crecimiento de las bacterias y hongos fue menor respecto al abono inoculado. Los resultados del conteo del hongo Trichoderma spp se compararon con la concentración inicial inoculada, obteniéndose los resultados ilustrados en la figura 3. 


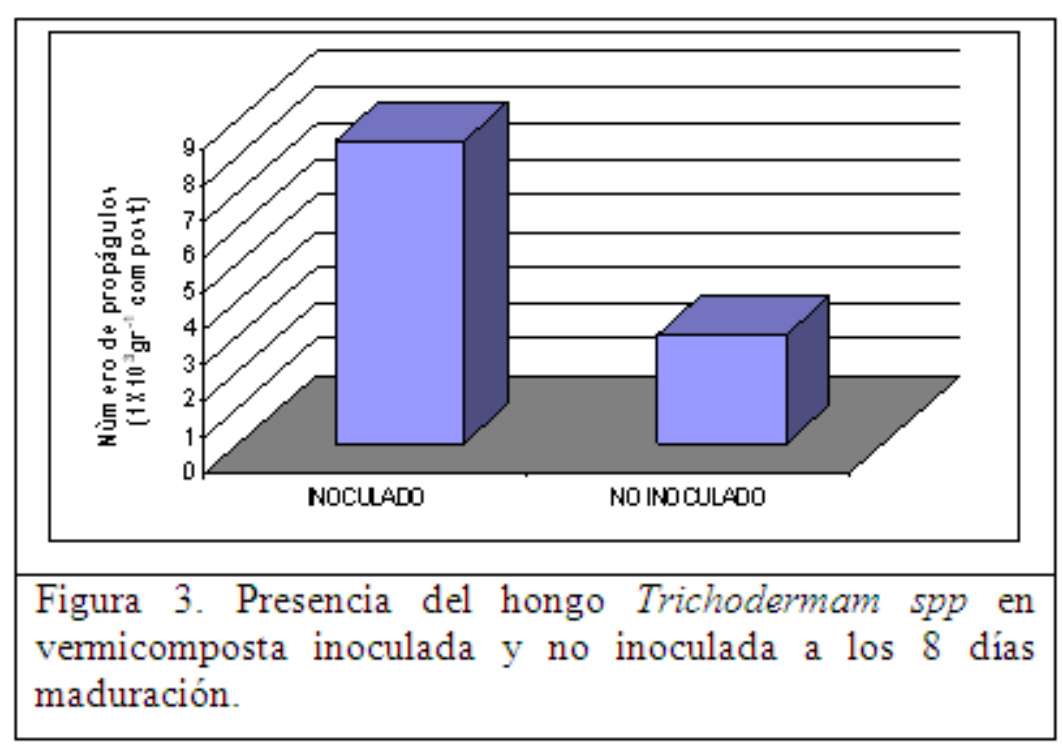

La concentración del hongo inoculado fue de 1.2 × 104 propágulos gr-1 de composta. La población del hongo Trichoderma spp obtenida a los 8 días fue de 8.4 × 103 propágulos gr-1 de compost. En contraste, en el compost no inoculado la lectura de la población de Trichoderma fue de 3.0 x10 3 propágulos gr-1 de compost. Se asumió un error de dilución de $25 \%$, bajo esta asunción se puede sugerir que no hubo ni incremento ni disminución en la población de Trichoderma.

Las razones por las cuales no se presentó incremento del hongo inoculado pueden deberse a varios factores como: condiciones ambientales adversas para un organismo foráneo; edad del compost, ya que a medida que el compost se vuelve más maduro pierde calidad en cuanto a aporte de nutrimentos para las bacterias y hongos; falta de una base de nutrimentos disponibles para el hongo en el momento de la inoculación o presencia de sustancias de difícil degradabilidad; competencia de otras razas de hongos por el nicho ecológico para obtener una mayor reproducción del hongo; características físicas o químicas del compost, lo cual también influye en la población de microorganismos, ya que cada uno de estos grupos tiene condiciones específicas para su crecimiento y reproducción al igual que el tipo de raza y manejo del vermicompost, entre otros factores.

\section{CONCLUSIONES}

Se puede concluir que la inoculación del hongo Trichoderma spp en la vermicomposta comercial no presentó un aumento ni disminución significativas en la población del hongo. Una de las posibles causas por las cuales no se presentó aumento del hongo Trichoderma spp pudo estar relacionada con la falta de condiciones óptimas para el crecimiento y reproducción del hongo.

En el compost inoculado después de los tres días se ve un aumento en la población de hongos y una disminución en la población de bacterias, esto probablemente se debió a un efecto supresivo por parte del hongo Trichoderma spp respecto a otros microorganismos presentes en el ambiente.

Se recomienda realizar otros experimentos con una primera dilución con $10 \mathrm{gr}$. de sustrato para aumentar la sensibilidad a diferencias en el conteo. 


\section{AGRADECIMIENTOS}

Al Dr. Carlos Ramírez por su asesoría en el análisis de los resultados de esta investigación. A Gerardina Umaña, M.Sc. por sus aportes en la etapa experimental y metodología de laboratorio. Ambos investigadores de la Universidad de Costa Rica, gracias a sus acertados comentarios.

\section{BIBLIOGRAFÍA}

- $\quad$ ALEXANDER, M. 1977. Introduction to soil microbiology. Second edition. Cornell University. John Wiley \& Sons. New York.

- $\quad$ CORlay, L; FERRERA, R; CERRATO; ETCHEVERS, J.D; ECHEGARAY, A y SANTIZO, J.A.1999. Cinética de grupos microbianos en el proceso de producción de composta y vermicomposta. In Agrociencia. 33:375-380. México.

- DALZELL, H.W, BIDDLESTONE; GRAY, K. R; THURAIRAJAN, K. 1987. Soil, management compost production and use in tropical and subtropical environments. Bulletin 56.FAO. 137p.

- $\quad$ FREEMAN, T.E.1981. Use of conidial fungi in biological control: In Biology of conidial fungi. Vol. 2. Edited by: GARRY, Y.COLE and BRYCE KENDRICK Academic Press. New York, USA. p. 146- 161.

- HENIS. YIGAL.1983. Ecological principles of biocontrol of soilborne plant pathogens: Trichoderma Model. In Current perspectives in Microbial ecology. American Society for Microbiology Washington, D.C.

- HOITINK, A.J and BOEHM, M, J. 1993. Mechanisms of suppression of soilborne plant pathogens in compost- amended substrates in Science and Engineering of Composting: design, environmental, Microbiological and utilization aspects.

- HOITINK, H.A. J and KEENER, H.M. (Eds.). The Ohio State University. LYNCH, J.M.1993. Substrate availability in the production of compost in: Science and Engineering of Composting: design, environmental, Microbiological and utilization aspects. HOITINK, H.A. J and KEENER, H.M.(Eds.). The Ohio State University.

1. Profesor Asistente, Departamento de Producción Pecuaria, Facultad de Medicina Veterinaria y Zootecnia. Grupo de Investigaciones en Sistemas Agroforestales Pecuarios. Universidad del Tolima.

2. Profesor Asociado, Departamento de Producción Pecuaria, Facultad de Medicina Veterinaria y Zootecnia. Grupo de Investigaciones en Sistemas Agroforestales Pecuarios. Universidad del Tolima. 